International Journal of Technology 13(1) 179-189 (2022)

Received August 2021 / Revised August 2021 / Accepted September 2021

International Journal of Technology

http://ijtech.eng.ui.ac.id

\title{
Impact of Lambda Value on Combustion Characteristics and Emissions of Syngas-Diesel Dual-Fuel Engine
}

\author{
Hussein A. Mahmood ${ }^{1 *}$, Ali O. Al-Sulttani², Naseer A. Mousa ${ }^{1}$, Osam H. Attia ${ }^{1}$ \\ ${ }^{1}$ Department of Reconstruction and Projects, University of Baghdad, Iraq \\ ${ }^{2}$ Department of Water Resources Engineering, College of Engineering, University of Baghdad, Iraq
}

\begin{abstract}
A deep understanding of the ignition characteristics of syngas-diesel under different lambda values is essential for the application of dual-fuel combustion. In this study, the effect of increasing the lambda value was examined along with the emission characteristics and engine performance of syngas-diesel dual-fuel engines under a constant syngas-to-diesel substitution ratio of $52 \%$ at $2000 \mathrm{rpm}$ engine speed. The work involved computational fluid dynamics analysis related to combustion for a four-stroke single-cylinder direct-injection engine. Combustion analysis was carried out using ANSYS Workbench (FLUENT) V16.1 software. According to the simulation results, the maximum pressure, temperature, and nitric oxide emission inside the combustion chamber increased with each increase in the value of lambda, while the emission of carbon dioxide and carbon monoxide decreased inside the engine.
\end{abstract}

Keywords: CFD; Combustion; Emission, Lambda; Syngas-diesel dual-fuel engine

\section{Introduction}

Internal combustion engines, and particularly diesel engines, have been utilized by the industrial, agricultural, and automotive sectors due to their low cost of operation, robustness, reliability, high efficiency, resilience, and robustness. Widespread use of engines that run on diesel fuel has resulted in a huge increase in demand for petroleum fuels, which will lead to their depletion. Due to the tremendous exploitation of the traditional petroleum fuels needed for obtaining diesel, it is vital that there is research on alternate fuels that minimize the need for traditional fuels and serve new application areas (Chintala \& Subramanian, 2013; Dhole et al., 2014; Mahmood et al., 2017a; Mahmood et al., 2017b; Said et al., 2018; Ali et al., 2019; Wibowo et al., 2020).

In spite of the significant use conventional diesel fuels, their emissions contribute to environmental pollution. In addition, unburnt hydrocarbons, carbon monoxide (CO), nitrogen oxides $\left(\mathrm{NO}_{\mathrm{x}}\right)$, particulate matter, sulfur oxides, and soot are the main pollutants emitted by engines operating on diesel fuel, particularly in urban areas with high population density. Such pollutants have a tendency to aggravate environmental problems such as acid rain, climate change, global warming, and smoke and have a detrimental impact on human health (Reşitoğlu et al., 2015; Ibrahim et al., 2016; Alhamdany et al., 2018; Vellaiyan et al., 2018; Hamid et al., 2020).

*Corresponding author's email: husseinadel@uobaghdad.edu.iq, Tel.: 009647739695778 doi: 10.14716/ijtech.v13i1.5060 
Because of the fast depletion of fossil fuels and growing concern for the climate and human health, both engine manufacturers and researchers are being forced to look for alternatives that are reliable, low-cost, and environmentally friendly. Biomass is one of the most promising alternative energy sources that researchers in the field of internal combustion engines have recently been focusing on (Said et al., 2018; Pathak et al., 2021) and can be defined as an environmentally friendly renewable resource. The fermentation or vaporization of different types of biomass goes on to form hydrogen-rich "synthesis gas (syngas)", which could be used as a main fuel for vehicles or as a partial substitute for traditional types of fuel (Anggraini et al., 2019; Krishnamoorthi et al., 2020). Syngas may be formed from many different raw materials through methane steam reforming, biomass fermentation, autothermal reforming of fossil fuel, ethanol steam reforming, ammonia cracking, partial methane oxidation, and other techniques. In addition, the syngas components acquired from various methods and materials can differ significantly. Carbon dioxide, hydrogen, methane, nitrogen, and carbon monoxide are the major elements of the syngas (Azimov et al., 2011; Feng, 2017; Stylianidis et al., 2017; Ali et al., 2019; Anggraini et al., 2019 ).

Two different methods have been devised for converting diesel engines for syngas, namely the syngas-dedicated and dual-fuel approaches. In the syngas-dedicated approach, ignition is achieved by (typically) using a spark plug, as in a gasoline engine, and the diesel injector is no longer used, following a suitable redesign of the engine's combustion chamber head. Furthermore, the air intake manifold must be changed to include a syngas injector, control valve, and control unit. The conversion of the engine from diesel to syngas results in a decrease in brake power. The dual-fuel approach, however, applies syngas as the main fuel along with small quantity of diesel as a pilot fuel for ignition. With regard to this approach to conversion, the engine's combustion chamber head is not changed due to the fact that spark plugs are also needed, while liquid fuel injection continues to be performed by an in-cylinder system of injection. Furthermore, due to the poor autoignition performance of syngas, a small amount of diesel is pumped into the engine's cylinder to ignite it when it is used as fuel in dual-fuel engines that work under compression ignition (Mahmood et al., 2016; Mahmood et al., 2019).

According to previous literature, little research has been conducted on modifying diesel engines to work under the dual-fuel mode for enhancing fuel economy and decreasing emissions. However, the majority of studies do not take into account the effect of an increase in the lambda value on the emission characteristics and engine performance of syngas-diesel engines. As a result, published work on mixing ratios, combustion characteristics, and pollution for dual-fuel engines with various lambda values remain limited. The goal of this research is to investigate the characteristics of diesel and syngas combustion against different lambda values (1,1.2, 1.4, and 1.6) under a constant replacement ratio of $52 \%$ at an engine speed of $2000 \mathrm{rpm}$.

\section{Methodology}

In this study, the commercial ANSYS Workbench (FLUENT) V16.1 CFD package was utilized for combustion simulations. In addition, The 3D pressure-based implicit unsteady solver was used for solving the main governing equations (energy, mass, momentum, and species). Furthermore, the equations were estimated (spatially) using the finite volume approach by means of a standard scheme with regard to pressure interpolation. The discretization approach for convective transport equations applied the first-order upwind scheme. The pressure-velocity coupling in discretized equations was achieved with the use of the semi-implicit method for pressure linked equations (SIMPLE) approach for solving 
the pressure field (Kongre and Sunnapwar, 2010). Also, for modelling the combustion, a premixed combustion model was utilized. The CFD combustion simulation was conducted in terms of a 4-stroke single-cylinder direct-injection diesel engine with a bore of $80.26 \mathrm{~mm}$, stroke of $88.9 \mathrm{~mm}$, and compression ratio of 20.36 (Alrazen et al., 2016).The syngas comprised $50 \%$ carbon monoxide and 50\% hydrogen. In a syngas-diesel engine, air and syngas fuel are mixed in the intake manifold before the intake stroke. The mixture is then compressed during the compression stroke, as in diesel engines. Since syngas fuel has a higher auto-ignition temperature, $0.0002673 \mathrm{~kg} / \mathrm{s}$ diesel fuel was pumped into the compression stroke end to ignite the blend. The numerical solution approach in ANSYS Workbench (FLUENT) applied a finite volume approach, staggered-grid arrangement, and unstructured mesh. Turbulence was simulated using the renormalized group model (Siddique et al., 2016; Ali et al., 2019; Das et al., 2019). Furthermore, the flow domain for simulation was a combustion chamber (Figure 1), and the exhaust valve, inlet valve, exhaust port, and intake port were ignored (Figure 1). Because of the problem's complexity, only a $30^{\circ}$ sector of the model was modeled using 3D software, as can be seen in Figure 2. Meshing was performed with the ANSYS meshed tool, as shown in Figure 3. A grid independence study was conducted to find the optimum grid to reduce computational time and improve the accuracy of the results. The grid independence test was achieved at an engine speed of $2000 \mathrm{rpm}$ with a lambda value of 1.2, as shown in Figure 4. According to the grid independence test, 323,587 elements were chosen to be the most appropriate for this study (Figure 4).

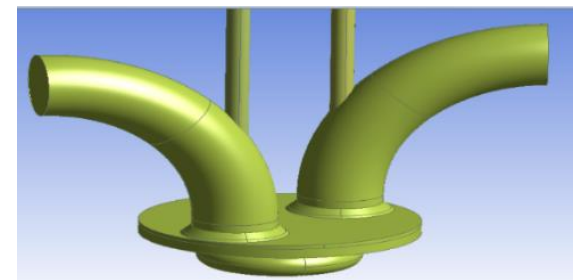

Figure1 The geometry of the engine, drawn using ANSYS Workbench software

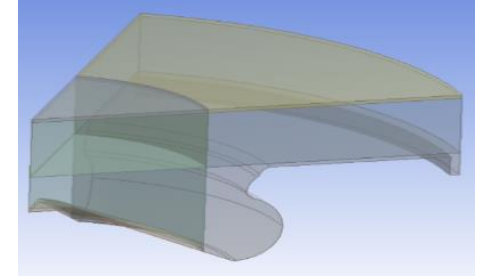

Figure 2 A $30^{\circ}$ section of combustion chamber geometry

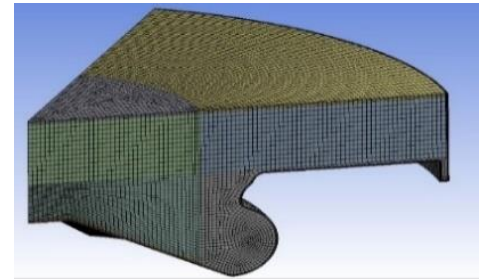

Figure 3 Meshing domain of combustion chamber geometry

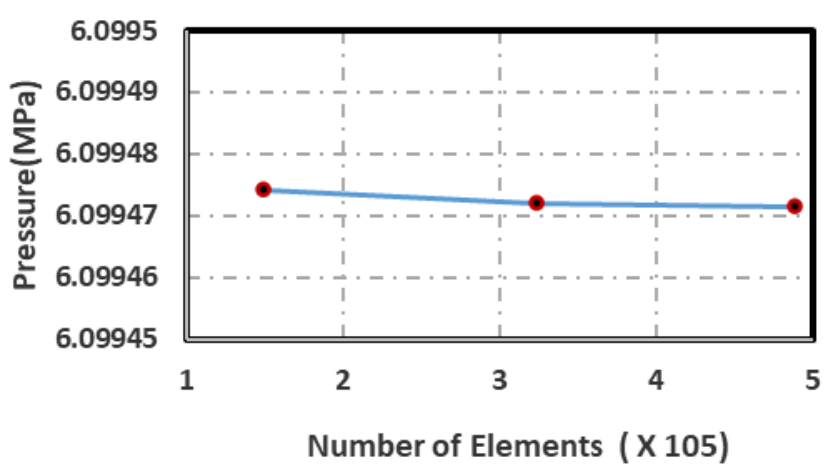

Figure 4 The grid independence test

\subsection{Combustion Model}

With ANSYS Workbench (FLUENT) software, the finite rate chemistry and species transport were used in the combustion model to simulate the process of combustion in a dual-fuel engine. This methodology was premised on the solution of transport equations for mass fractions of species. In the species transport equations, the reaction rate term is calculated from Arrhenius rate expressions. 


\subsection{Chemical Kinetic Mechanism}

Issues with turbulent combustion mathematical modelling concern turbulent flow along with chemical kinetics and the relation between flow and chemical reactions. The inhomogeneous pattern that results from the combination of turbulence and chemical reactions is well recognized. In the current study, ANSYS Workbench software was used for modeling syngas-diesel combustion. To model turbulent combustion, the finite rate/eddy dissipation model was utilized. Diesel combustion involves various reaction steps and chemical species, and for that, a mechanism derived from the decreased alkanes combustion mechanism of Jones and Lindstedt (1988) and Ali et al. (2020) was developed. Diesel reaction $\left(\mathrm{C}_{12} \mathrm{H}_{23}\right)$ includes four global sequences of reactions defined by the following equations.

$$
\begin{gathered}
\mathrm{C}_{12} \mathrm{H}_{23}+6 \mathrm{O}_{2} \rightarrow 12 \mathrm{CO}_{2}+11.5 \mathrm{H}_{2} \\
\mathrm{C}_{12} \mathrm{H}_{23}+12 \mathrm{H}_{2} \rightarrow 12 \mathrm{CO}+23.5 \mathrm{H}_{2} \\
\mathrm{H}_{2}+0.5 \mathrm{O}_{2} \\
\mathrm{CO}+\mathrm{H}_{2} \mathrm{O} \rightarrow \mathrm{CO}_{2}+\mathrm{H}_{2} \mathrm{O}
\end{gathered}
$$

With the syngas consisting of 50\% carbon monoxide and $50 \%$ hydrogen in the current study, the carbon monoxide hydrogen reactions involved three steps of global reaction depending on Alrazen et al. (2016), Ali et al. (2020), Stylianidis et al. (2017), and Tsang et al. (1986), as shown below.

$$
\begin{gathered}
\mathrm{O}_{2}+\mathrm{CO} \rightarrow \mathrm{CO}_{2}+\mathrm{O} \\
\mathrm{H}_{2} \mathrm{O}+\mathrm{CO} \rightarrow \mathrm{CO}_{2}+\mathrm{H}_{2} \\
0.5 \mathrm{O}_{2}+\mathrm{H}_{2} \rightarrow \mathrm{H}_{2} \mathrm{O}
\end{gathered}
$$

The three equations that comprise the extended Zeldovich reaction, commonly known as thermal NO, are as follows.

$$
\begin{array}{ccc}
N_{2}+O & \leftrightarrow O+N \\
N+O_{2} & \leftrightarrow & N O+O \\
N+O H & \leftrightarrow & N O+H
\end{array}
$$

\subsection{Lambda Value}

The lambda value $(\lambda)$ is one of the most important factors affecting combustion characteristics inside the engine. Lambda is the ratio between the actual air-fuel ratio inside the engine and the stoichiometric air-fuel ratio inside it. The latter ratio is the amount of air needed to complete the combustion of fuel. Internal combustion engines do not function at the stoichiometric air-fuel ratio, but rather at ratios close to it, which is the actual ratio of the air to the fuel. The lambda value is computed as follows.

$$
\operatorname{lambda}(\lambda)=\frac{(m a / m f) \text { Actual }}{(m a / m f) \text { stoichiometric }}
$$

where $m a$ is the mass of air, and $m f$ is the mass of fuel. Lambda is classified into three types: (1) stoichiometric $(\lambda=1)$; (2) rich mixture-air deficiency $(\lambda<1)$; and (3) lean mixtureexcess air $(\lambda>1)$. In this study, four values of lambda $(1,1.2,1.4$, and 1.6) have been used to investigate the characteristics of diesel and syngas combustion under dual-fuel phase with a constant replacement ratio of $52 \%$ at $2000 \mathrm{rpm}$ engine speed.

\section{Validation Model}

For validation, an engine model with a single cylinder was built and simulated. The engine characteristics and other engine data were derived from the engine properties of Alrazen et al. (2016) under specific conditions, such as an engine speed of $2000 \mathrm{rpm}$, temperature of $330 \mathrm{~K}, 1.2 \lambda$ value, and $50 \%$ replacement ratio for CNG fuel with diesel fuel. A $3 \mathrm{D}$ combustion chamber was modeled and validated by comparing it with a set of 
numerical data for CNG-diesel dual-fuel engine operation according to Alrazen et al. (2016). Moreover, to validate the results of the simulation, the pressure value in the combustion chamber was compared with the simulation results of Alrazen et al. (2016). The in-cylinder pressure validation in this study is shown in Figure 5. Generally, at most points of the simulation, data appear to be in close agreement with their numerical results.

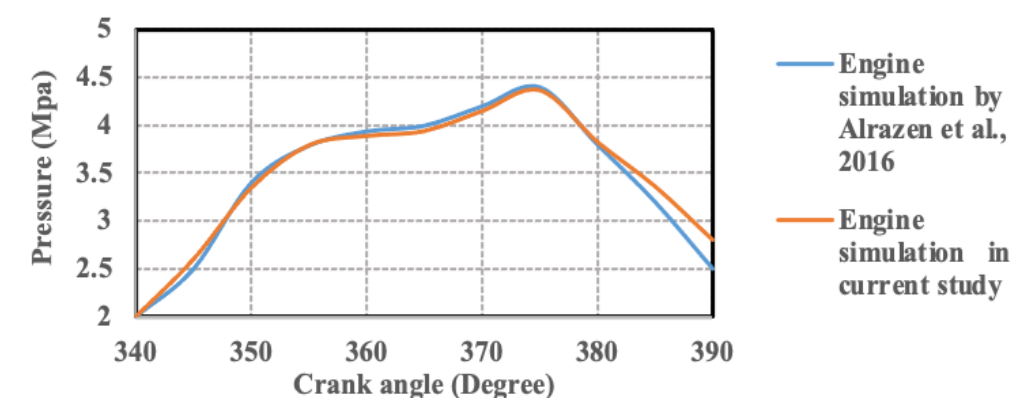

Figure 5 Validation of a single-cylinder engine model working under dual-fuel mode at $2000 \mathrm{rpm}$ engine speed

\section{Results and Discussion}

In this paper, a CFD analysis of combustion for the syngas-diesel engine with different lambda values was studied and presented with a $2000 \mathrm{rpm}$ engine speed and a constant replacement ratio for diesel fuel with syngas of 52\%. The computations were initially for the combustion simulation inside the dual-fuel engine at a crank angle of 310 degrees before top dead center (TDC), and finally at 420 degrees after TDC. This included the stroke of compression and the combustion stroke. The primary temperature and pressure within the combustion chamber model were defined for solving the governing equations. The primary pressure was $20,000,000$ pa and the primary temperature was $800 \mathrm{~K}$. The time step utilized for each degree of crank angle was 0.25 . The results of the combustion simulation for the syngas-diesel engine are illustrated below.

\subsection{Pressure}

Figure 6 depicts the effect of different lambda values on the pressure inside the combustion chamber according to crank angle. It can be seen that when the lambda value increases, so too does the pressure inside the combustion chamber.

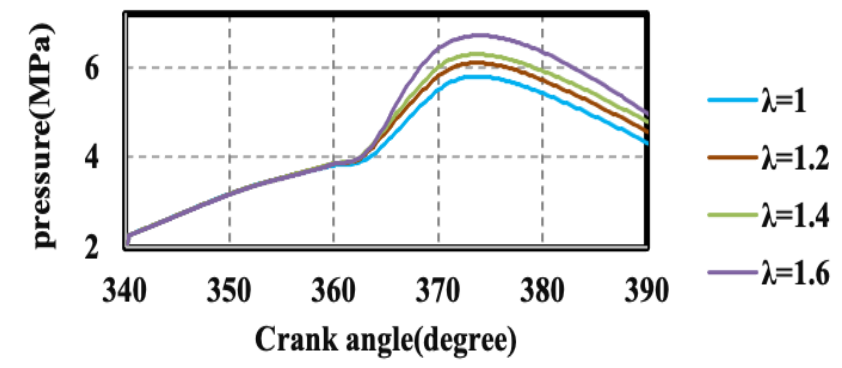

Figure 6 Effect of lambda values on the pressure inside the combustion chamber according to crank angle

In addition, the peak pressure would increase from 5,800,428 $\mathrm{Pa}$ to 6,099,471 $\mathrm{Pa}, 6,291,275$ $\mathrm{Pa}$, and 6,708,188 $\mathrm{Pa}$ for lambda values of $1,1.2,1.4$, and 1.6, respectively. This is because an increase in the amount of air enables almost complete combustion of the syngas and air mixture while the pressure in the cylinder increases with raising energy produced by a mixture of the fuel and air. Thus, the pressure in the combustion chamber increases progressively as the lambda value is increased. Figure 7 identifies the spatial distribution 
of pressure inside the dual-fuel engine at the various lambda values. It shows that the distribution of pressure and the location of its formation inside the cylinder are enhanced with increased lambda values inside the dual-fuel engine.
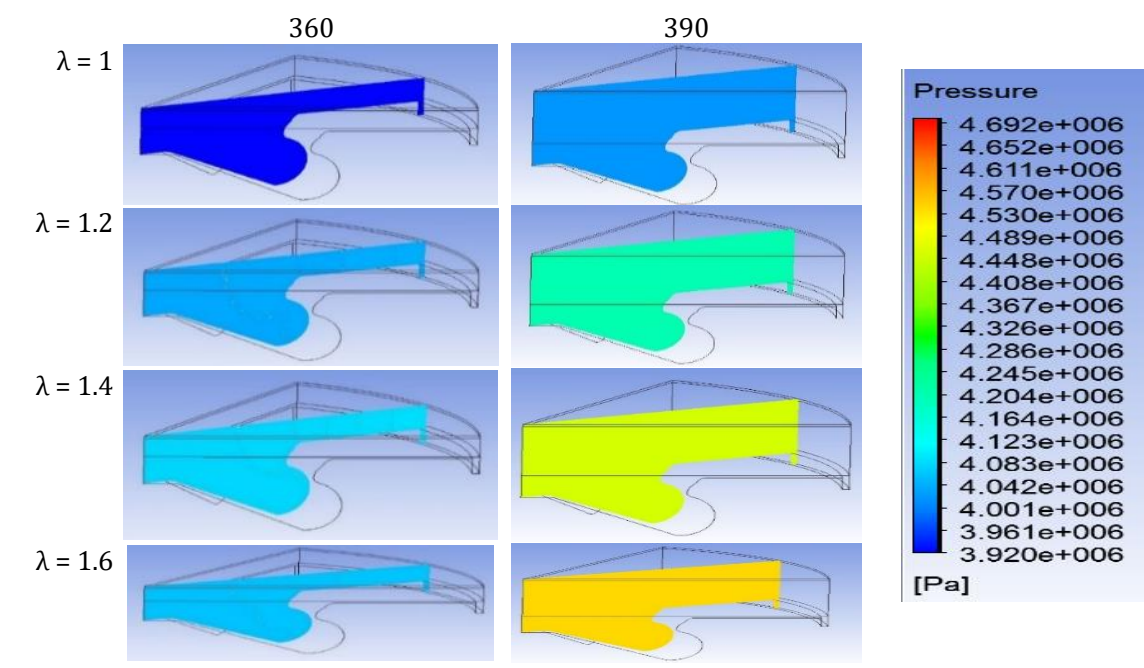

Figure 7 Spatial distribution of pressure

\subsection{Temperature}

Figure 8 shows the effect of different lambda values on the temperature inside the combustion chamber according to crank angle. It can be seen that when the lambda ratio is raised, the maximum temperature inside the combustion chamber also increases. In addition, the peak temperature in the cylinder would increase from $2348 \mathrm{~K}$ to $2507 \mathrm{~K}, 2644$ $\mathrm{K}$, and $2790 \mathrm{~K}$ for lambda values of $1,1.2,1.4$, and 1.6, respectively. This is due to the fact that increasing the value of lambda allows the almost complete combustion of syngas and air mixture as the temperature in the cylinder increases with additional energy produced by the mixture of fuel and air. Therefore, the temperature in the cylinder is directly proportional to the increased lambda value. Figure 9 depicts the spatial distribution of temperature inside a dual-fuel engine at the various lambda values. It demonstrates that the distribution of temperature and the location of its formation inside the cylinder are enhanced with each increase in the lambda value inside the dual-fuel engine.

\subsection{Carbon Monoxide}

Figure 10 shows the effect of lambda values on the emission of carbon monoxide according to crank angle. It demonstrates that carbon monoxide emission in the combustion chamber reduces as the lambda value increases. In addition, the carbon monoxide mass fraction values inside the engine would decrease from 0.012865317 to $0.009972716,0.007938363$, and 0.006670433 for lambda values of $1,1.2,1.4$, and 1.6, respectively. This is due to the fact that carbon monoxide emission is typically primarily influenced by the ratio of air to fuel, and the gas is one of the by-products of incomplete burning of fuel-air blend. When the engine works under a lean mixture, so that the lambda value is high, the concentration of air is rich in the air-fuel mixture; therefore, all of the carbon can convert into carbon dioxide and not form carbon monoxide. In other words, carbon monoxide emission in the cylinder is inversely proportional to the increased value of lambda. Figure 11 illustrates the spatial distribution of the carbon monoxide inside the dual-fuel engine at each lambda value. It explains that the distribution and the regions where these were formed inside the combustion chamber reduced with each increase of excess air inside the dual-fuel engine. 


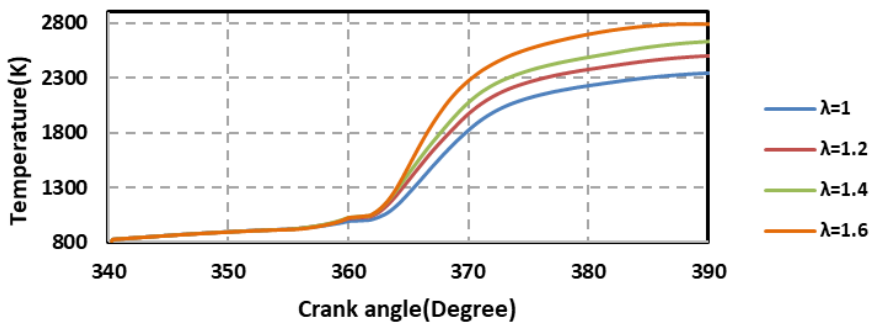

Figure 8 Effect of lambda values on the temperature inside the combustion chamber according to crank angle
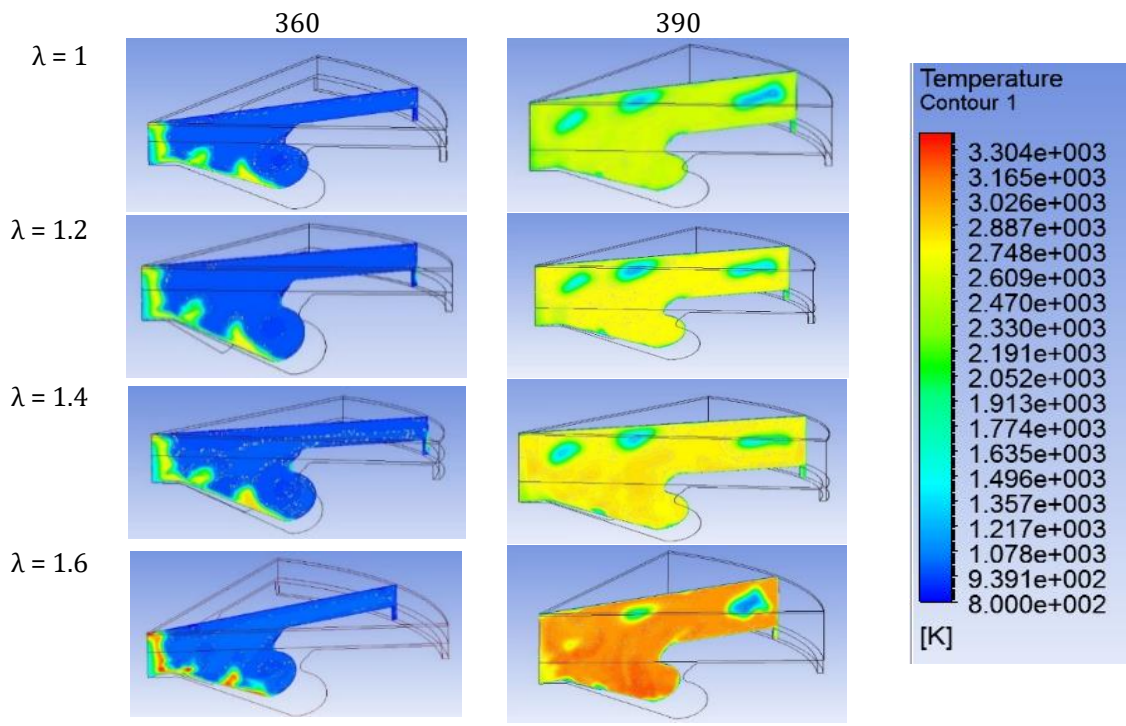

Figure 9 Spatial distribution of temperature

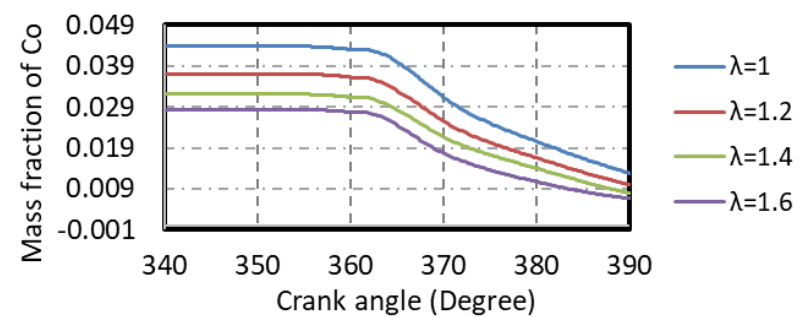

Figure 10 Effect of lambda values on CO emission according to crank angle
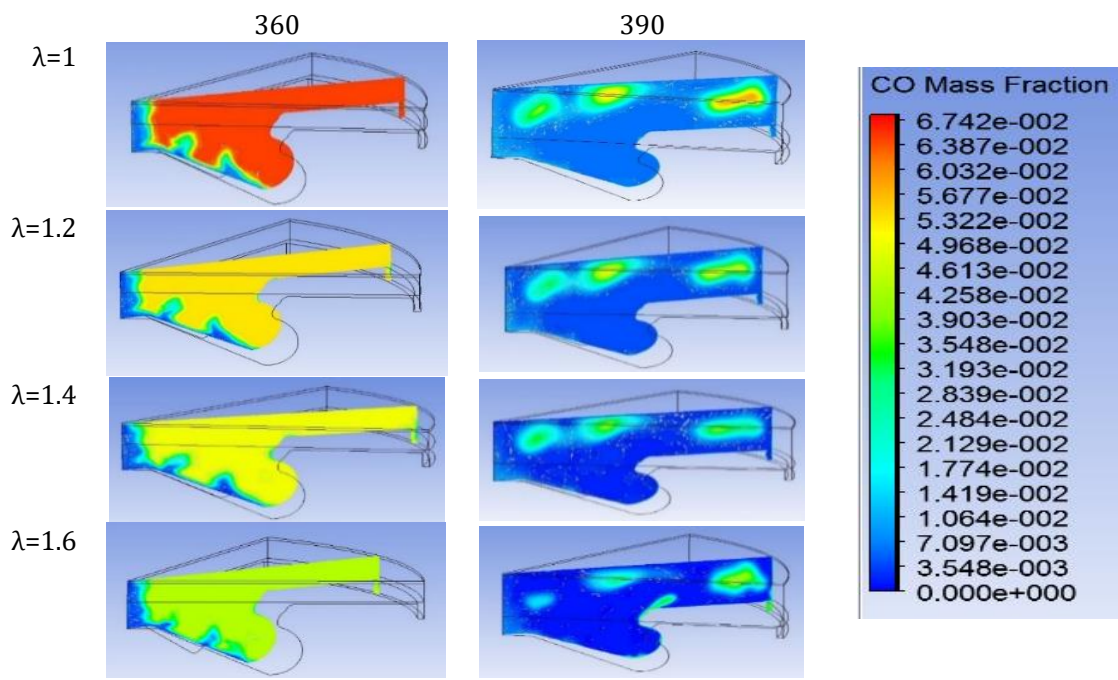

Figure 11 Spatial distribution of CO emission 


\subsection{Carbon Dioxide}

Figure 12 summarizes the effect of each lambda value on carbon dioxide emission according to crank angle. It demonstrates that when the lambda value rises, the concentration of carbon dioxide emissions in the cylinder decrease rapidly inside the engine. Furthermore, the carbon dioxide mass fraction values inside the engine reduced from 0.000546097 to $0.00048523,0.000414978$, and 0.027892221 for lambda values of 1 , $1.2,1.4$, and 1.6, respectively. Figure 13 demonstrates the spatial distribution of carbon dioxide emission inside the combustion chamber under dual-fuel mode with different lambda values. It shows that the diffusivity of carbon dioxide emission and the regions where its emission was formed inside the combustion chamber reduce with each increasing lambda value.

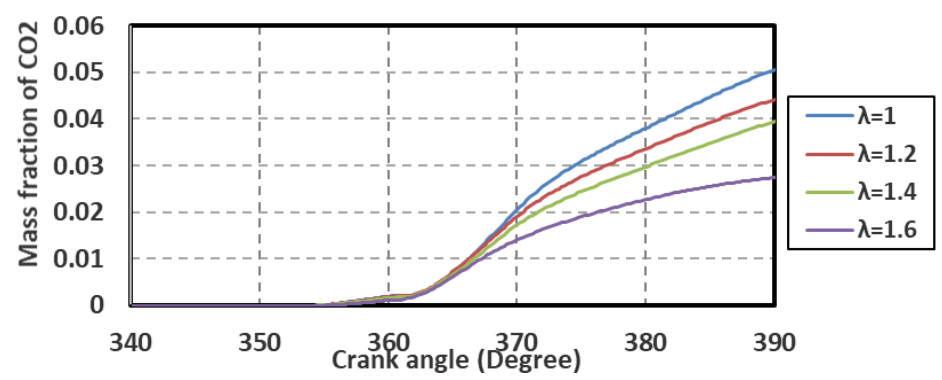

Figure 12 Effect of lambda values on carbon dioxide emission according to crank angle

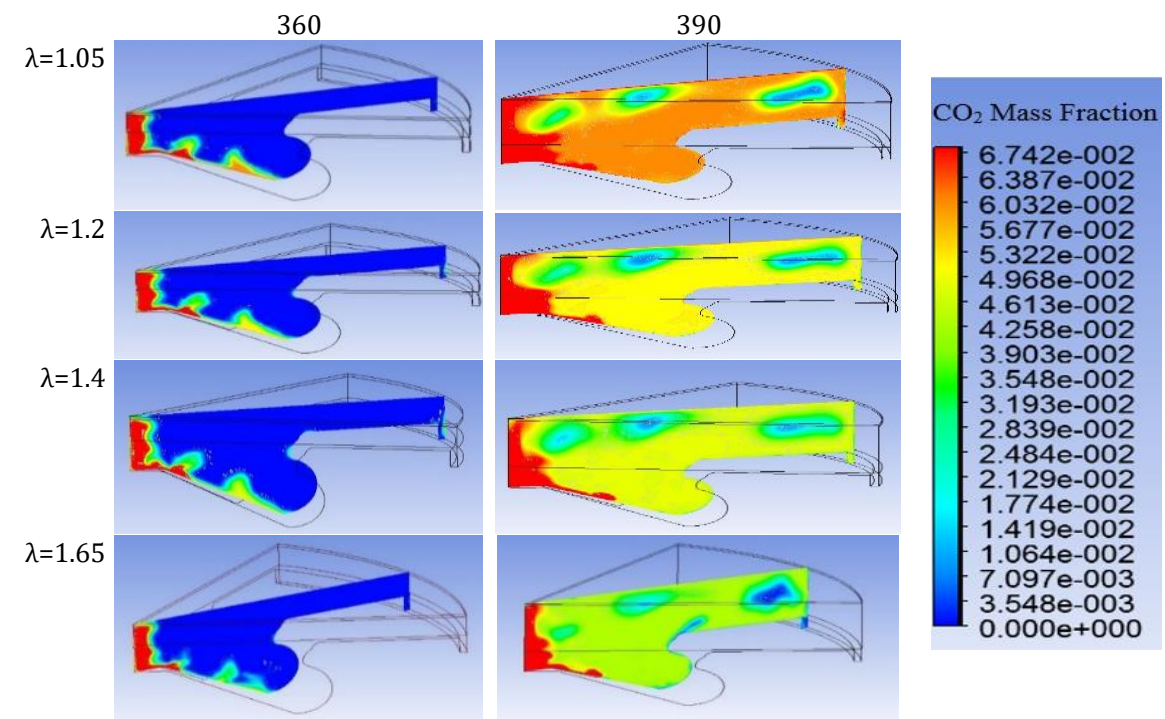

Figure 13 Spatial distribution of carbon dioxide emissions

\subsection{Nitric oxide emission}

Figure 14 explains the effect of lambda values on nitric oxide emission according to crank angle and demonstrates that the spatial distribution of nitric oxide emission the syngas-diesel engine at each different lambda value. As exhibited in Figures 14 and 15, nitric oxide emission increase with each increase in excess air. Moreover, the nitric oxide mass fraction values inside the engine would raise from 0.00554054 to 0.006849439 , 0.007600012 , and 0.011217929 for lambda values of $1,1.2,1.4$, and 1.6 , respectively. This is due to the fact that the amount of the nitric oxide produced is a function of maximal temperature in the cylinder, residence time, and oxygen concentration, since a rise in nitric oxide is closely related to the engine's temperature and oxygen content. As a result, as the lambda value increases, nitric oxide emissions in the combustion chamber increase progressively. 


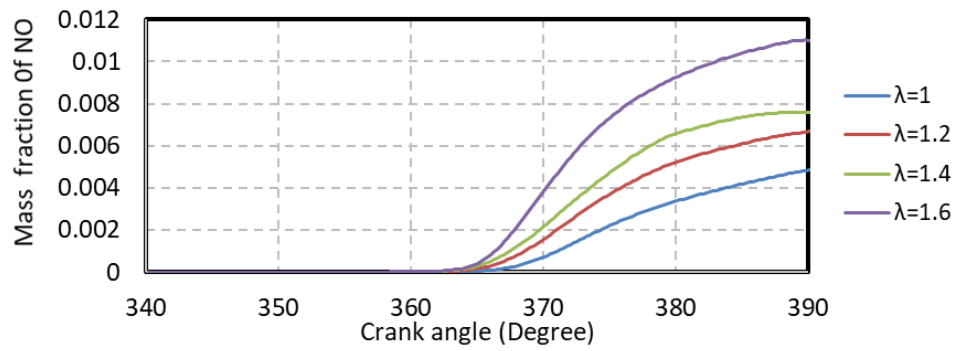

Figure 14 Effect of lambda values on nitric oxide emission according to crank angle
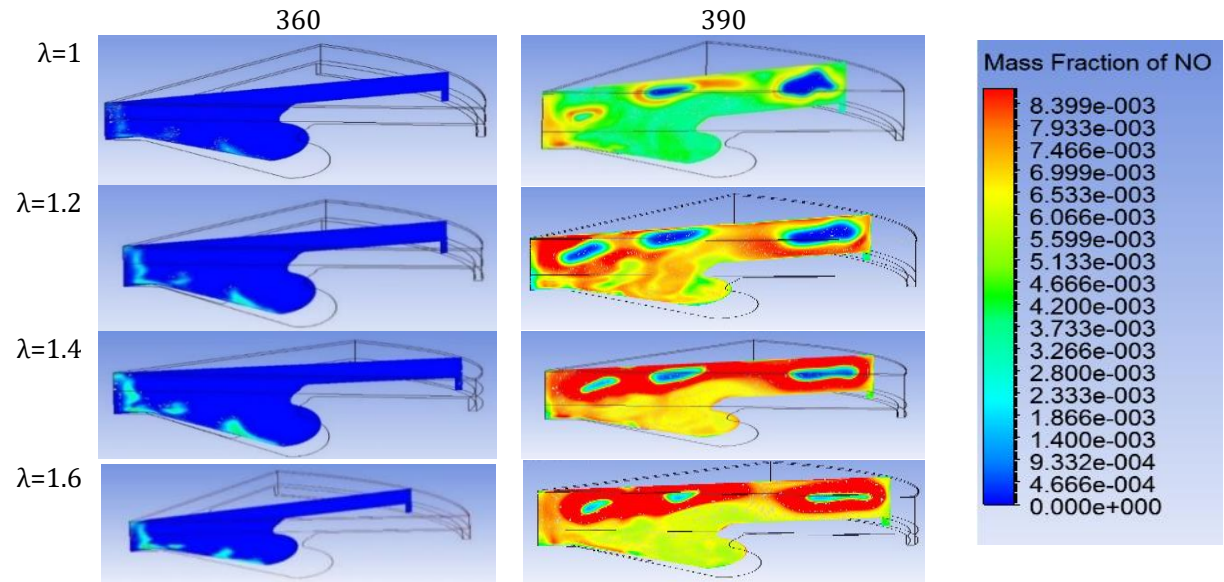

Figure 15 Spatial distribution of nitric oxide emission

\section{Conclusions}

In this study, the emission and combustion characteristics in syngas-diesel dual-fuel engines at different lambda values were numerically investigated using ANSYS Workbench (FLUENT) software. The main results are outlined from the investigation as follows: (1) At a constant replacement ratio for diesel fuel with syngas of $52 \%$, combustion performance improved with increased air content in the combustion chamber. Moreover, the maximum pressure and temperature in the combustion chamber increased with each increase in the lambda value. Moreover, the peak pressure increased from 5,800,428.603 $\mathrm{Pa}$ to 6,099,471.415 $\mathrm{Pa}, 6,291,275.301 \mathrm{~Pa}, 6,708,188.479 \mathrm{~Pa}$, and 6,708,188 $\mathrm{Pa}$ for lambda values of 1,1.2, 1.4, and 1.6, respectively; (2) At a constant replacement ratio of $52 \%$ for diesel fuel with syngas, increases in air content led to decreases in the emission of carbon dioxide and carbon monoxide inside the engine, along with an increase in nitric oxide emission. In addition, the carbon monoxide mass fraction values inside the engine decreased from 0.012865317 to $0.009972716,0.007938363$, and 0.006670433 for lambda values of $1,1.2$, 1.4 , and 1.6, respectively. Moreover, the nitric oxide mass fraction values inside the engine raised from 0.00554054 to $0.006849439,0.007600012$, and 0.011217929 for lambda values of $1,1.2,1.4$, and 1.6 , respectively.

\section{References}

Alhamdany, A.A., Hameed, A.Q., Salman, Q.M., 2018. Experimental Investigation for the Removal of Toxic Gases from Vehicle Exhaust using Non-Thermal Plasma. Journal of Engineering, Volume 24(8), pp. 55-70

Ali, A.A.M.M., Ali, K., Kim, C., Lee, Y., Oh, S., Kim, K., 2019. Numerical Study of the Combustion Characteristics in a Syngas-Diesel Dual-Fuel Engine Under Lean Condition. International Journal of Automotive Technology, Volume 20(5), pp. 933-942 
Ali, R., Raheemah, S.H., Al-Mayyahi, N.N., 2020. Numerical Analysis of Combustion Characteristics and Emission of Dual and Tri-Fuel Diesel Engine Under Two Engine Speeds. Jordan Journal of Mechanical \& Industrial Engineering, Volume 14(2), pp. 205213

Alrazen, H.A., Talib, A.A., Ahmad, K., 2016. A Two-Component CFD Studies of the Effects of $\mathrm{H}_{2}, \mathrm{CNG}$, and Diesel Blend on Combustion Characteristics and Emissions of a Diesel Engine. International Journal of Hydrogen Energy, Volume 41(24), pp. 10483-10495

Anggraini, I.D., Keryanti, M.T.A.P.K., Purwadi, R., Noda, R., Watanabe, T., Setiadi, T., 2019. Bioethanol Production Via Syngas Fermentation of Clostridium Ljungdahlii in a Hollow Fiber Membrane Supported Bioreactor. International Journal of Technology, Volume 10(3), pp. 481-490

Azimov, U., Okuno, M., Tsuboi, K., Kawahara, N., Tomita, E., 2011. Multidimensional CFD Simulation of Syngas Combustion in a Micro-Pilot-Ignited Dual-Fuel Engine using a Constructed Chemical Kinetics Mechanism. International Journal of Hydrogen Energy, Volume 36(21), pp. 13793-13807

Chintala, V., Subramanian, K., 2013. A CFD (Computational Fluid Dynamics) Study for Optimization of Gas Injector Orientation for Performance Improvement of a Dual-Fuel Diesel Engine. Energy, Volume 57, pp. 709-721

Das, S., Debnath, B.K., Das, R.S., Stagni, A., Faravelli, T., 2019. Numerical Investigation of a Porous Media Combustor in a Small-Scale Diesel Engine. Energy, Volume 186, https://doi.org/10.1016/j.energy.2019.07.115

Dhole, A., Yarasu, R., Lata, D., Priyam, A., 2014. Effect on Performance and Emissions of a Dual Fuel Diesel Engine using Hydrogen and Producer Gas as Secondary Fuels. International Journal of Hydrogen Energy, Volume 39(15), pp. 8087-8097

Feng, S., 2017. Numerical Study of the Performance and Emission of a Diesel-Syngas Dual Fuel Engine. Mathematical Problems in Engineering, Volume 2017, https://doi.org/10.1155/2017/6825079

Hamid, M.F., Idroas, M.Y., Mohamed, M., Sa'ad, S., Yew Heng, T., Che Mat, S., Miskam, M.A., Abdullah, M.K., 2020. Numerical Investigation of the Characteristics of the In-Cylinder Air Flow in a Compression-Ignition Engine for the Application of Emulsified Biofuels. Processes, Volume 8(11), pp. 1-17

Ibrahim, F., Wan Mahmood, W., Abdullah, S., Abu Mansor, M., 2016. Numerical Investigation of Soot Mass Concentration in Compression Ignition Diesel Engine. Journal of Mechanical Engineering and Sciences, Volume 10, pp. 2275-2287

Jones, W., Lindstedt, R., 1988. Global Reaction Schemes for Hydrocarbon Combustion. Combustion and Flame, Volume 73(3), pp. 233-249

Kongre, U.V., Sunnapwar, V.K., 2010. CFD Modeling and Experimental Validation of Combustion in Direct Ignition Engine Fueled with Diesel. International Journal of Applied Engineering Research, Volume 1(3), pp. 508-517

Krishnamoorthi, M., Sreedhara, S., Duvvuri, P.P., 2020. Experimental, Numerical and Exergy Analyses of a Dual Fuel Combustion Engine Fuelled with Syngas and Biodiesel/Diesel Blends. Applied Energy, Volume 263, https://doi.org/10.1016/j.apenergy.2020.114643

Mahmood, H.A., Adam, N.M., Sahari, B., Masuri, S., 2017a. Design of Compressed Natural GasAir Mixer for Dual Fuel Engine using Three-Dimensional Computational Fluid Dynamics Modeling. Journal of Computational and Theoretical Nanoscience, Volume 14(7), pp. 3125-3142

Mahmood, H.A., Adam, N.M., Sahari, B., Masuri, S., 2017b. New Design of a CNG-H 2 -AIR Mixer for Internal Combustion Engines: An Experimental and Numerical Study. Energies, 
Volume 10(9), pp. 1-27

Mahmood, H.A., Adam, N.M., Sahari, B.B., Masuri, S.U., 2016. Investigation on the Air-Gas Characteristics of Air-Gas Mixer Designed for Bi-Engines. International Journal of Applied Engineering Research, Volume 11(12), pp. 7786-7794

Mahmood, H.A., Adam, N.M., Sahari, B.B., Masuri, S.U., Ahmed, H.E., 2019. An investigation of Air-Gas Mixer Types Designed for Dual-Fuel Engines: Review. Journal of Engineering and Applied Sciences. Volume 14(4), pp. 1014-1033

Pathak, S.K., Nayyar, A., Goel, V., 2021. Optimization of EGR Effects on Performance and Emission Parameters of a Dual Fuel (Diesel + CNG) CI Engine: An Experimental Investigation. Fuel, Volume 291, https://doi.org/10.1016/j.fuel.2021.120183

Reşitoğlu, İ.A., Altinişik, K., Keskin, A., 2015. The Pollutant Emissions from Diesel-Engine Vehicles and Exhaust Aftertreatment Systems. Clean Technologies and Environmental Policy, Volume 17(1), pp. 15-27

Said, N.H., Ani, F., Said, M.F.M., 2018. Emission and Performance Characteristics of Waste Cooking Oil Biodiesel Blends in a Single Direct Injection Diesel Engine. International Journal of Technology, Volume 9(2), pp. 238-245

Siddique, A., Azeez, S.A., Mohammed, R., 2016. Simulation and CFD Analysis of Various Combustion Chamber Geometry of a CI Engine using CFX. International Refereed Journal of Engineering and Science, Volume 5(8), pp. 33-39

Stylianidis, N., Azimov, U., Maheri, A., Tomita, E., Kawahara, N., 2017. Chemical Kinetics and CFD Analysis of Supercharged Micro-Pilot Ignited Dual-Fuel Engine Combustion of Syngas. Fuel, Volume 203, pp. 591-606

Tsang, W., Hampson, R., 1986. Chemical Kinetic Data Base for Combustion Chemistry. Part I. Methane and Related Compounds. Journal of Physical and Chemical Reference Data, Volume 15(3), pp. 1087-1279

Vellaiyan, S., Amirthagadeswaran, K., Sivasamy, D.B., 2018. Taguchi-Grey Relation Based Multi-Response Optimization of Diesel Engine Operating Parameters with Water-InDiesel Emulsion Fuel. International Journal of Technology, Volume 9(1), pp. 68-77

Wibowo, C.S., Setiady, N.I., Masuku, M., Hamzah, A., Fedori, I., Nugroho, Y.S., Sugiarto, B., 2020. The Performance of a Spark Ignition Engine using 92 RON Gasoline with Varying Blends of Bioethanol (E40, E50, E60) Measured using a Dynamometer Test. International Journal of Technology, Volume 11(7), pp. 1380-1387 